\title{
Ultrasensitive Measurement of Both SARS-CoV-2 RNA and Antibodies from Saliva
}

\author{
Supplementary Information
}

Table of contents:

1) Detailed Experimental Methods

2) Figure S1: RNA extraction optimizations

3) Table S1: Clinical characteristics of COVID-19+ saliva samples

4) Figure S2: Detection of SARS-CoV-2 RNA and antibodies from saliva samples of hospitalized COVID-19 patients over time

5) Figure S3: Antibody profiles in saliva samples

6) Figure S4: Direct detection of SARS-CoV-2 RNA using Simoa

7) Table S2: Spike and recovery in control saliva samples 


\section{Detailed Experimental Methods:}

\section{Saliva samples}

For protocol optimization and control experiments we used pooled human saliva in $1 \mathrm{~mL}$ aliquots from BiolVT. Saliva was spiked with heat-inactivated SARS-CoV-2 viral particles (ATCC) at the beginning of the protocol or with SARS-CoV-2 synthetic RNA (Twist Bioscience) after Proteinase K treatment. COVID-19 positive and negative saliva samples were obtained from adult patients presenting to Massachusetts General Hospital (MGH). Seven samples were from patients who tested negative for SARS-CoV2 using RT-qPCR from nasopharyngeal (NP) swabs and 9 samples were from patients who tested positive for SARS-CoV-2 using RT-qPCR from NP swabs. Pre-pandemic control samples were purchased from BioIVT. Samples were centrifuged at $13,150 \times \mathrm{g}$ at $4^{\circ} \mathrm{C}$ for $10 \mathrm{~min}$. The supernatant was removed and used for RNA and antibody detection. All saliva samples were collected under approval of the Mass General Brigham Institutional Review Board for Human Subjects Research.

RNA extraction using custom protocol

RNA extractions were done in 96-well LoBind PCR plates (Eppendorf) or $2000 \mu \mathrm{L}$ Deepwell plates (Eppendorf). Proteinase $\mathrm{K}$ and SDS were added to one volume of saliva $(30 \mu \mathrm{L}$ or $300 \mu \mathrm{L}$ ) to a final concentration of $0.5 \%$ SDS and 20x Proteinase $\mathrm{K}$ (New England Biolabs) and saliva was incubated at $65^{\circ} \mathrm{C}$ for 30 minutes. Two volumes of lysis buffer consisting of 6M Guanidinium Thiocyanate (Millipore Sigma) and 0.5\% Triton X100 (ThermoFisher Scientific) were then added and mixed by pipetting. Sera-Mag Carboxylate-Modified Magnetic Beads (Cytiva), used at $10 \mu \mathrm{L}$ per reaction, were washed twice in $1 \mathrm{~mL}$ water and resuspended in an equivalent volume of lysis buffer. Beads in lysis buffer $(10 \mu \mathrm{L})$ were then added to each reaction. Three volumes of isopropyl alcohol (Millipore Sigma) were added to each reaction, and the samples were mixed well by pipetting up and down ten times. Samples were incubated for five minutes at room temperature to allow RNA to bind to beads, and then placed on a magnet. When solution cleared (approximately 2 minutes for small-volume extraction or 15-20 minutes for largevolume extraction), with the plate still on the magnet, supernatant was removed. When using low-volume $(200 \mu \mathrm{L})$ plates: beads were washed twice with $150 \mu \mathrm{L}$ of $70 \%$ ethanol. Ensuring that all of the ethanol is removed, RNA was then eluted using $10 \mu \mathrm{L}$ of nuclease-free water. When using high-volume (deep-well) plates: $150 \mu \mathrm{L}$ of $70 \%$ ethanol was added and beads were resuspended in $70 \%$ ethanol off of the magnet and transferred to a PCR plate. The PCR plate was then placed on magnet and supernatant was removed. Another $150 \mu \mathrm{L}$ of $70 \%$ ethanol was added to the deep-well plate to get any residual beads and transferred to beads on the PCR plate. One last $70 \%$ ethanol wash step was then performed on the PCR plate and all $70 \%$ ethanol removed. RNA was eluted using either $20 \mu \mathrm{L}$ (for recovery experiments) or $10 \mu \mathrm{L}$ (for comparison to other methods) of nuclease-free water.

\section{RNA extraction comparison}

For all comparison experiments, pooled human saliva spiked in with heat-inactivated virus at 50 particles $/ \mu \mathrm{L}$ was used. For the comparison of the custom protocol to the commercial kit, ThermoFisher Scientific MagMAX Viral/Pathogen Nucleic Acid Isolation was used according to manufacturer's protocol with either $200 \mu \mathrm{L}$ input volume or $400 \mu \mathrm{L}$ input volume and $50 \mu \mathrm{L}$ elution volume. For the comparison to the no-extraction protocols, saliva with virus was transferred to PCR strip tubes for inactivation. For the $95^{\circ} \mathrm{C}$ protocol, saliva was heated at $95^{\circ} \mathrm{C}$ for 5 minutes. For the TCEP protocol, Tris(2- 
carboxyethyl)phosphine hydrochloride (Millipore Sigma) was dissolved in water, EDTA was added to a final concentration of $0.1 \mathrm{M}$, and $\mathrm{NaOH}$ was added until the TCEP solution reached a $\mathrm{pH}$ of 8 . This TCEP solution was added 1:100 to saliva and heated at $95^{\circ} \mathrm{C}$ for 5 minutes. For the SalivaDirect Proteinase K protocol, $50 \mu \mathrm{L}$ saliva was added to $6.25 \mu \mathrm{L}$ of Proteinase K, Molecular Biology Grade (New England Biolabs). The tube was then vortexed at $3200 \mathrm{RPM}$ for 1 minute and heated at $95^{\circ} \mathrm{C}$ for 5 minutes. For all no-extraction methods, $8.2 \mu \mathrm{L}$ of inactivated saliva was used as input into the RT-qPCR.

$R T-q P C R$

Viral RNA was quantified using Luna Universal Probe One-Step RT-qPCR kit (New England Biolabs) according to the manufacturer's protocol in a CFX96 Real-Time Detection System (Bio-Rad). All RT-qPCR reactions were performed using CDC N1 primers ${ }^{1}$ (IDT), targeting the $\mathrm{N}$-gene of SARS-CoV-2, used at a final concentration of $0.4 \mu \mathrm{M}$ with the probe at $0.2 \mu \mathrm{M}$. Sequences are: Forward:

GACCCCAAAATCAGCGAAAT, Reverse: TCTGGTTACTGCCAGTTGAATCTG, Probe: FAM-ACCCCGCATTACGTTTGGTGGACC-BHQ1. For each reaction, $8.2 \mu \mathrm{L}$ (of purified RNA or inactivated saliva) input was used together with $10 \mu \mathrm{L}$ Luna Master Mix, $1 \mu \mathrm{L}$ Luna Enzyme Mix, and $0.8 \mu \mathrm{L}$ primer/probe mix. For each RNA extraction optimization or comparison experiment, an aliquot of SARS-CoV-2 synthetic RNA (Twist Bioscience) or heat-inactivated SARS-CoV-2 viral particles (ATCC) was run on the same RT-qPCR plate. Differences in RT-qPCR cycle threshold $(\mathrm{Ct})$ values between the sample and inplate control (ex. 10,000 viral particles) were calculated using the equation:

Relative RNA Level $=2^{-\Delta C t}$.

Simoa antibody measurements in saliva

SARS-CoV-2 antibody measurements were performed as previously described ${ }^{2}$. The saliva samples were 100-fold diluted in ThermoFisher Scientific StartingBlock T20 Blocking Buffer (PBS) with 1X Halt Protease Inhibitor Cocktail (ThermoFisher Scientific) with EDTA. The Simoa assays were performed on the automated HD-X Analyzer (Quanterix). IgG, IgA and IgM against RBD, S1, spike, and nucleocapsid were measured in duplicate and the average AEB (average enzyme per bead) for each interaction was calculated.

\section{Direct SARS-CoV-2 RNA detection with Simoa}

Single Molecule Arrays (Simoa) have previously been adapted for direct detection of nucleic acids ${ }^{3,4}$. Here, we have developed a Simoa assay for the direct detection of SARS-CoV-2 RNA. Paramagnetic beads were conjugated to 5' aminated LNA capture oligos using EDC and Sulfo-NHS, as previously described ${ }^{4}$. We based our capture and detector sequences on the EU SARS-CoV-2 PCR primer set ${ }^{5}$. We used the EU Reverse $(R)$ primer sequence, modified with LNA nucleotides and a poly-A extender, as a capture probe (SI Figure 3b). EU Forward (F) and Probe (P) sequences were biotinylated and used as detector probes. All capture and detector oligos were purchased from IDT.

Beads were prepared at concentrations of 240,000 beads $/ \mu \mathrm{L}$ using an equal ratio of capture beads and three different dye encoded helper beads (Quanterix). The purpose of the dye-encoded helper beads is to reduce the number of capture beads required for the assay (preserving reagents), and to modestly increase the sensitivity of the assay, as previously described ${ }^{6} .50 \mu \mathrm{L}$ of samples were added to a low-binding 96-well plate (Corning), and $5 \mu \mathrm{L}$ of well-mixed bead solution were added to each sample. To inactivate RNases, $2 \mu \mathrm{L}$ of Proteinase $\mathrm{K}$ were added to each sample, and the plate was sealed, incubated at $60^{\circ} \mathrm{C}$, and shaken at 1200 RPM for 30 minutes using an Eppendorf 
Thermomixer C. EDTA was added to the solution at a final concentration of $0.1 \mathrm{mM}$. The plate was again sealed and incubated with shaking for 2 hours to allow bead-conjugated capture oligos to hybridize with the target RNA.

The plate was then moved to a magnet, and beads were washed twice with $150 \mu$ l of $0.22 \mu \mathrm{m}$ filtered Hybridization Buffer (HB) (5x saline-sodium citrate [SSC] in diethyl pyrocarbonate [DEPC]-treated water). Detector solution was prepared by diluting EU $F$ and EU P biotinylated probes to a final concentration of 25nM in HB. Beads were resuspended in $50 \mu \mathrm{L}$ of $\mathrm{HB}$, and $5 \mu \mathrm{L}$ of Detector Solution was added to each sample. The plate was again incubated with shaking for 30 minutes at $60^{\circ} \mathrm{C}$ to allow detector probes to hybridize to the target RNA.

Beads were reconstituted in Dilution Buffer (1x sodium chloride-sodium phosphateEDTA [SSPE] and 1.6\% dextran sulfate in DEPC-treated water) and transferred onto a new 96-well plate (Quanterix). Streptavidin- $\beta$-galactosidase (S $\beta G$ ) Concentrate (Quanterix) was diluted to 50pM in S $\beta$ G Diluent (Quanterix). The new plate and diluted S $\beta$ G were loaded onto an HD-X analyzer (Quanterix). We used a 2-step assay and loaded Wash Buffer 1 in place of on-board beads and detectors. Beads were resuspended on-board in $100 \mu \mathrm{L}$ of $S \beta G$, incubated for 20 minutes (27 cadences), washed, resuspended with resorufin $\beta$-D-galactopyranoside (RGP) (Quanterix), and loaded into a microwell array for imaging.

All synthetic RNA spike in experiments used Twist Biosciences RNA standard. Sensitivity was greatly increased when RNA was fragmented. Thus, synthetic SARSCoV-2 RNA was fragmented using Zinc-based RNA fragmentation reagent (ThermoFisher Scientific) at $70^{\circ} \mathrm{C}$ for 5 minutes before being spiked into samples, according to the manufacturer's instructions. 
Figure S1: RNA Extraction Optimizations

A
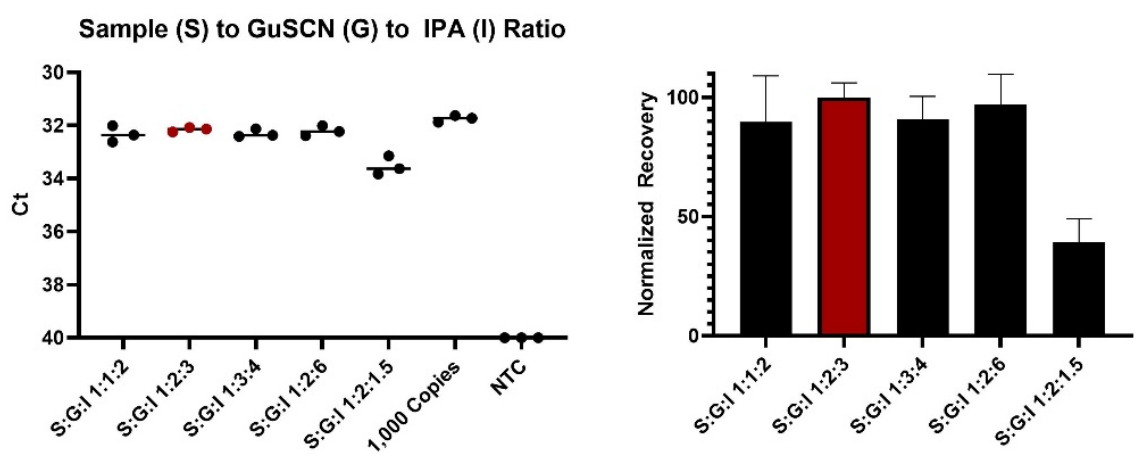

B.

Elution Temperature
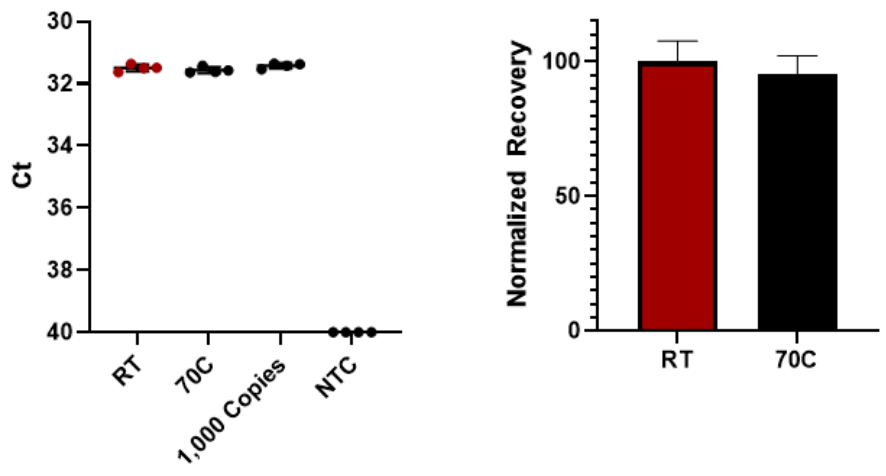

C

Buffers

D
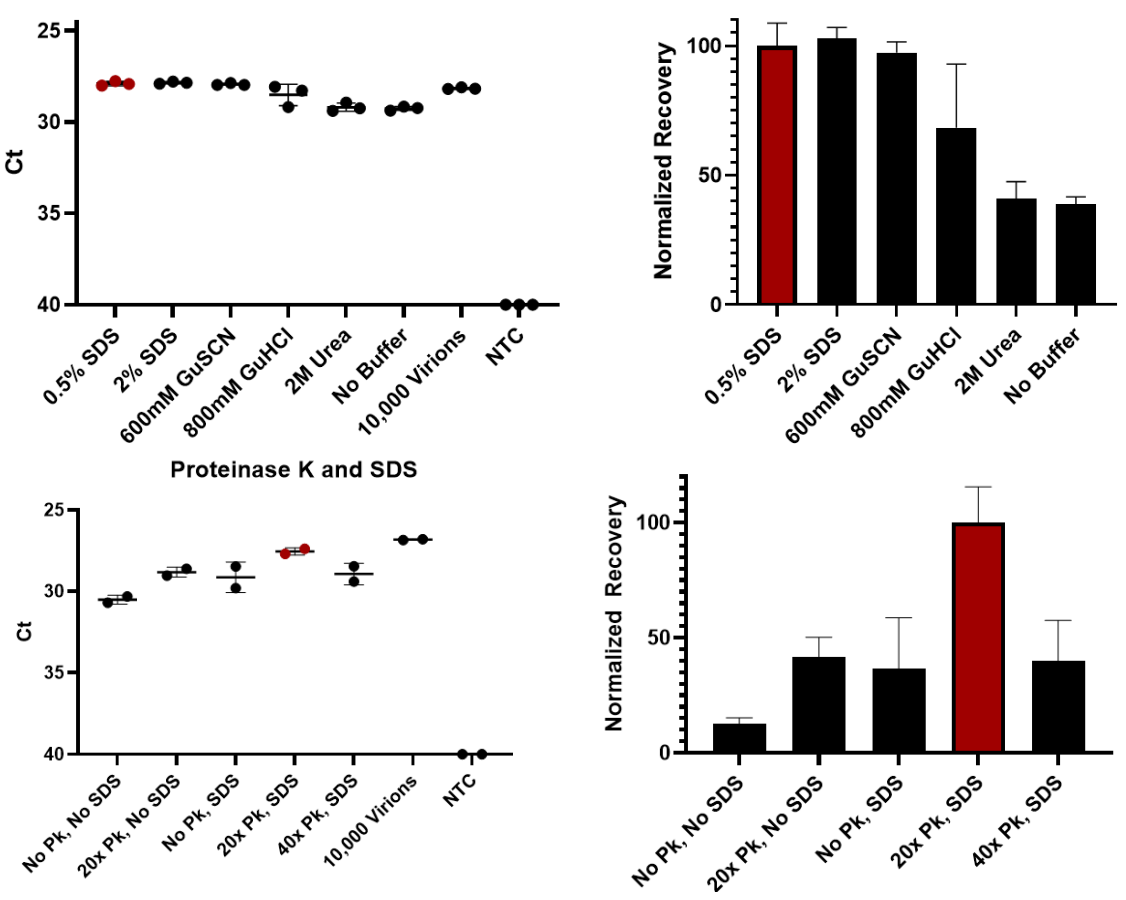
Figure S1: RNA extraction optimizations.

Selected optimization experiments comparing extracted viral RNA to heat-inactivated virus or synthetic SARS-CoV-2 RNA by RT-qPCR. NTC - No Template Control. Conditions were signal is undetected (NTC) are set to $\mathrm{Ct}=40$. A) Optimization of volumetric ratios of sample (PBS), guanidinium thiocyanate (GuSCN) and isopropyl alcohol (IPA) spiked with 1,000 copies of synthetic SARS-CoV-2 RNA. B) Comparison of elution water temperatures from 30uL PBS spiked with 1,000 copies of synthetic SARSCoV-2 RNA. There was no significant difference ( $p=0.4088$, ns) between eluting RNA using room-temperature water versus eluting in water warmed to $70^{\circ} \mathrm{C}$. C) Comparison of additives to enhance Proteinase K activity during the RNase inactivation step in $30 \mu \mathrm{L}$ saliva spiked with virus. D) Comparison of Proteinase K activity and SDS in $300 \mu \mathrm{L}$ of saliva spiked with virus. Recovery plots shown are normalized to final protocol (Custom Protocol: $0.5 \%$ SDS, Volumetric Ratios of Sample:GuSCN:IPA 1:2:3, 20x Proteinase K, RT elution, denoted by red color).

\section{Table S1: Clinical Characteristics of Saliva Samples}

\begin{tabular}{|l|c|c|}
\hline Patient characteristics & NP PCR Positive $(\mathbf{n}=\mathbf{9})$ & NP PCR Negative $(\mathbf{n}=\mathbf{7})$ \\
\hline Age $\left(25^{\mathrm{n}}, 75^{\mathrm{n}}\right.$ quartile) & $38.9(29,47)$ & $30.7(36,27)$ \\
\hline Male & 4 & 2 \\
\hline Fever & 4 & 4 \\
\hline Cough & 7 & 2 \\
\hline SOB & 4 & 3 \\
\hline Sore throat & 5 & NA \\
\hline Myalgia & 2 & 1 \\
\hline Obesity & 3 & 1 \\
\hline Immunosuppression & NA & 1 \\
\hline Lung disease & 2 & NA \\
\hline Heart disease & NA & NA \\
\hline Required Ventilation & NA & 1 \\
\hline UTI & NA & NA \\
\hline Death & NA & 3 \\
\hline
\end{tabular}


Figure S2: Antibody Profiles in COVID-19+ Saliva Samples

Nucleocapsid

RBD

Spike

S1
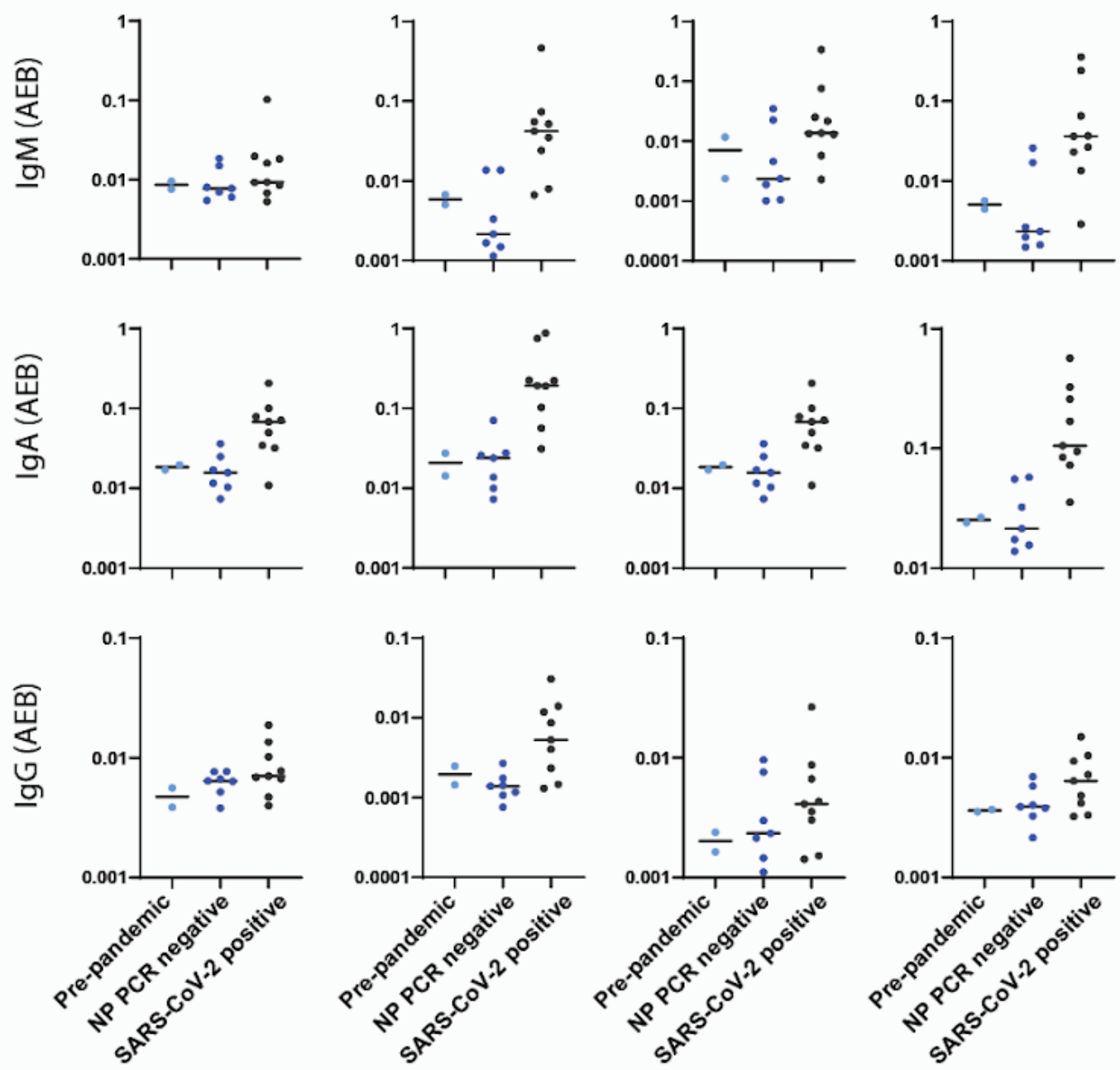

Figure S2: Profiling antibodies in saliva samples.

Simoa antibody assay results for $\lg G$, $\lg M$, and $\lg A$ against the four viral targets: spike, S1 subunit, RBD, and nucleocapsid for pre-pandemic samples (light blue, $n=2$ ), NP RTqPCR negative samples (blue, $n=7$ ) and positive samples (dark blue, $n=9$ ). Black lines indicate the median normalized AEB (average enzyme per bead) value of each population. 
Figure S3: Detection of SARS-CoV-2 RNA and Antibodies from Saliva Samples of Hospitalized COVID-19 Patients Over Time

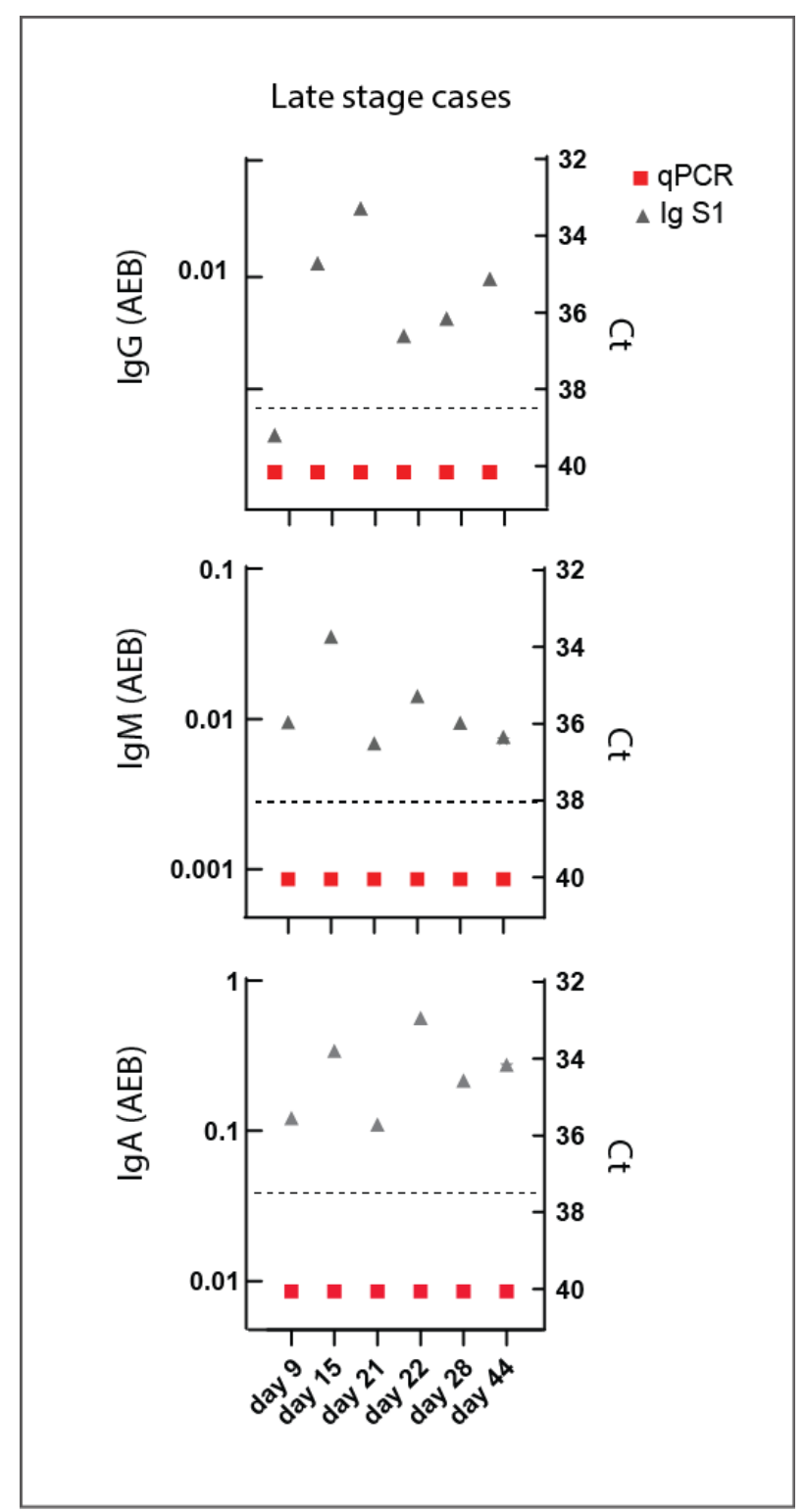

Figure S3: Detection of viral RNA and antibodies from saliva of COVID-19 patients over time (day 0 corresponds to initial hospitalization). RT-qPCR Ct levels (red rectangular) and Simoa antibody mean AEB (average enzyme per bead) levels (gray triangles) for $\lg G$, $\lg M$, and $\lg A$ against $S 1$ subunit. Conditions were signal is undetected are set to $\mathrm{Ct}$ $=40$. 
Figure S4: Direct Detection of SARS-CoV-2 RNA in Simoa

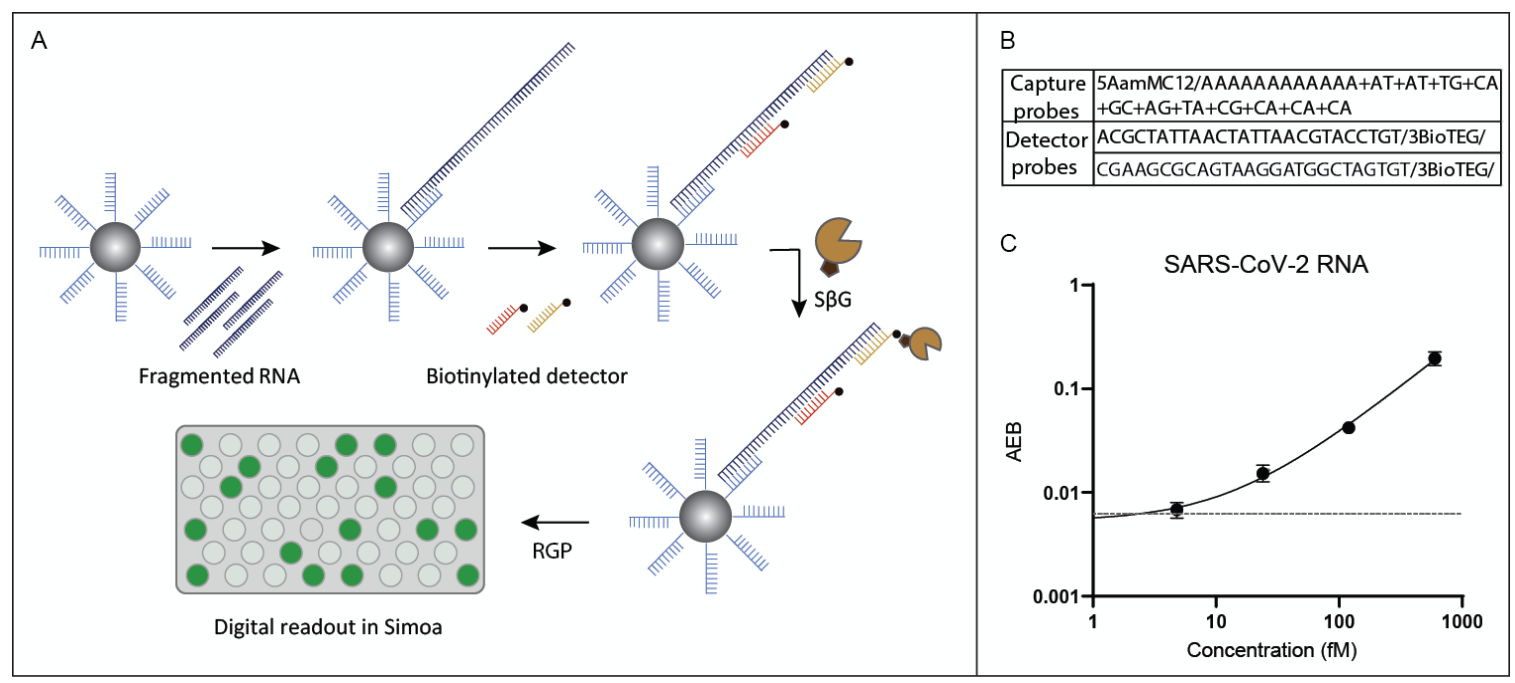

Figure S4: Direct detection of SARS-CoV-2 RNA in Simoa.

A) Schematic overview of Simoa RNA detection. Paramagnetic beads are conjugated with 5' aminated capture oligos using EDC and Sulfo-NHS chemistry. Detection is done in three steps: 1) conjugated beads capture RNA, 2) biotinylated detector sequences hybridize with target RNA, 3) streptavidin beta-galactosidase binds to biotinylated detectors. The beads are finally resuspended with resorufin $\beta-D$-galactopyranoside (RGP) (Quanterix), and loaded into a microwell array for imaging. B) List of capture and detector sequences employed (5' to 3'). C) A calibration curve of synthetic SARS-CoV-2 RNA standard depicts a limit of detection (LOD) of 3.4fM RNA, or 102,000 copies of RNA, using our Simoa based SARS-CoV-2 direct detection assay.

Table S2: Spike and Recovery in Control Saliva Samples

\begin{tabular}{|c|c|c|c|}
\hline Analyte & Saliva Concentration & Water Concentration & Recovery (\%) \\
\hline SARS-CoV-2 RNA & $222.07 \mathrm{fM}$ & $243.64 \mathrm{fM}$ & 91.1 \\
\hline IgG Spike & $61.83 \mathrm{ng} / \mathrm{mL}$ & $51.95 \mathrm{ng} / \mathrm{mL}$ & 119.0 \\
\hline IgG S1 & $69.76 \mathrm{ng} / \mathrm{mL}$ & $77.19 \mathrm{ng} / \mathrm{mL}$ & 90.4 \\
\hline $\operatorname{IgG~RBD}$ & $96.17 \mathrm{ng} / \mathrm{mL}$ & $89.33 \mathrm{ng} / \mathrm{mL}$ & 107.6 \\
\hline IgM Spike & $70.25 \mathrm{ng} / \mathrm{mL}$ & $70.00 \mathrm{ng} / \mathrm{mL}$ & 100.4 \\
\hline $\operatorname{IgM~S1}$ & $147.27 \mathrm{ng} / \mathrm{mL}$ & $155.65 \mathrm{ng} / \mathrm{mL}$ & 94.6 \\
\hline $\operatorname{IgM~RBD}$ & $272.34 \mathrm{ng} / \mathrm{mL}$ & $244.28 \mathrm{ng} / \mathrm{mL}$ & 111.5 \\
\hline IgA Spike & $88.02 \mathrm{ng} / \mathrm{mL}$ & $59.12 \mathrm{ng} / \mathrm{mL}$ & 148.9 \\
\hline $\operatorname{IgA~S1}$ & $54.19 \mathrm{ng} / \mathrm{mL}$ & $57.48 \mathrm{ng} / \mathrm{mL}$ & 94.3 \\
\hline $\operatorname{IgA~RBD~}$ & $64.49 \mathrm{ng} / \mathrm{mL}$ & $58.53 \mathrm{ng} / \mathrm{mL}$ & 110.2 \\
\hline
\end{tabular}

SARS-CoV-2 negative control saliva and water samples were spiked with SARS-CoV-2 RNA and anti-SARS-CoV-2 IgG, IgM, and IgA antibodies against spike protein (CR3022). Samples were split, and RNA and antibody levels were detected simultaneously using the Simoa platform. For RNA, samples were diluted $4 x$ into Hybridization Buffer (5x saline-sodium citrate [SSC] in diethyl pyrocarbonate [DEPC]- 
treated water). For antibody measurement, samples were diluted 100x into Sample Diluent (Quanterix). Recovery was measured as the percent of signal detected in saliva relative to water.

\section{References:}

1. CDC. CDC 2019-Novel Coronavirus [2019-NCoV] Real-Time RT-PCR Diagnostic Panel.; 2020. https://www.fda.gov/media/134922/download

2. Norman M, Gilboa T, Ogata AF, et al. Ultrasensitive high-resolution profiling of early seroconversion in patients with COVID-19. Nat Biomed Eng. Published online 2020. doi:10.1038/s41551-020-00611-x

3. Wang $X$, Walt DR. Simultaneous detection of small molecules, proteins and microRNAs using single molecule arrays. Chem Sci. 2020;11(30):7896-7903. doi:10.1039/D0SC02552F

4. Cohen L, Hartman MR, Amardey-Wellington A, Walt DR. Digital direct detection of microRNAs using single molecule arrays. Nucleic Acids Res. 2017;45(14):e137e137. doi:10.1093/nar/gkx542

5. Corman VM, Landt O, Kaiser M, et al. Detection of 2019 novel coronavirus (2019nCoV) by real-time RT-PCR. Eurosurveillance. 2020;25(3). doi:https://doi.org/10.2807/1560-7917.ES.2020.25.3.2000045

6. Kan CW, Tobos Cl, Rissin DM, et al. Digital enzyme-linked immunosorbent assays with sub-attomolar detection limits based on low numbers of capture beads combined with high efficiency bead analysis. Lab Chip. 2020;20(12):21222135. doi:10.1039/DOLC00267D 